\title{
Effect of exposure to lead on postural control in workers
}

\author{
N Ratzon, P Froom, E Leikin, E Kristal-Boneh, J Ribak
}

\begin{abstract}
Objectives-To examine the effect of lead on postural control of workers who have been exposed to lead.

Methods-63 Male, lead battery workers mean (SD) age 41.0 (7.4) were compared with 48 age matched male controls after excluding those with acute or chronic diseases. Exposed workers had mean (SD) past blood lead concentrations of 37.5 (9.2) $\mu \mathrm{g} / \mathrm{dl}$ and $11.2(5.7)$ years of employment. Postural control was measured with a computerised postural sway measurement system which measured both sway and total movements.

Results-Workers standing straight with eyes open on the bare plates had sway and total movements which were not notably different from controls. On the other hand increased movements were needed in the exposed workers to maintain stability (the general stability quotient $18.2(5.4) v 15.4$ (4.4) in controls, $p<0.01)$ when standing directly on the footplates with closed eyes, , and with the head tilted (15.0 (3.8) $v$ $11.5(3.0)$ in controls, $p<0.001)$. Exposed workers also had a trend for less ability to synchronise anterior posterior and lateral sway in the stress positions $(0.0625)$ than had non-exposed workers . Significant but low correlations were found between the estimate of the chronic internal dose of lead and three of 10 of the postural control measurements, and present lead blood concentrations and only one of the 10 measurements and ( $r$ values ranged from 0.21 to $0.31, \mathrm{p} \leqslant 0.03)$.

Conclusions-These findings suggest that lead affects postural control in asymptomatic workers. Further studies are warranted to find whether workers with decreased postural control are at increased risk of accidents and the relation, if any, of these measurements with subsequent morbidity.

(Occup Environ Med 2000;57:201-203)
\end{abstract}

Accepted 20 October 1999
Keywords: postural stability; equilibrium; exposure to lead

Exposure to low concentrations of lead may result in central and peripheral nervous system damage $^{1-16}$ with a dose-response relation ${ }^{4}$ and persistence of effects years after the end of exposure..$^{781014}$ Effects in workers exposed to lead include decreased central nervous conduction, ${ }^{12}$ cognitive impairment, ${ }^{4-6}$ extrapyramidal signs, ${ }^{3}$ and peripheral neuropathies. ${ }^{2} 7-10$

Although persistent postural instability was first shown in a case report of a construction carpenter with blood lead concentrations (PbBs) as high as $109 \mu \mathrm{g} / \mathrm{dl},{ }^{15}$ few studies have been done subsequently. Increased sway has been reported in battery manufacturing workers ${ }^{16} 17$ and in workers exposed to lead stearate $^{18}$ compared with controls, but the effects of altering proprioreception or vestibular inputs except for vision have not been studied previously, nor have the number of movements needed to maintain stability. In this study we compared the postural stability of 78 lead battery workers with 78 controls.

\section{Methods}

SUBJECTS

Seventy eight male workers at a lead battery production plant were compared with 78 age matched healthy blue collar workers of similar sex and education (table 1). The healthy controls were chosen after those with acute and chronic disease were excluded. All exposed workers were tested but 15 workers exposed to lead had chronic or acute illnesses at the time of the examination and therefore were excluded from further analysis. Also, 30 controls were eliminated because they were seamen. This left 63 exposed workers and 48 controls. Current $\mathrm{PbB}$ concentrations among lead workers ranged from 16 to $77 \mu \mathrm{g} / \mathrm{dl}$ (mean (SD) $42.5(12.7) \mu \mathrm{g} / \mathrm{dl})$ whereas mean concentrations of lead exposure over the total years of employment ranged between 19 and 55 (mean (SD) $37.5(9.2) \mu \mathrm{g} / \mathrm{dl}$ ). Current mean $\mathrm{PbB}$ concentration among control workers was 4.5 (2.6) $\mu \mathrm{g} / \mathrm{dl}$. Testing was conducted by one physician who took venous blood samples, measured equilibrium, and helped workers to fill out a questionnaire about demographic variables, past exposures, and anamnestic variables. All subjects were tested in a single session conducted in a quiet room.

BLOOD LEAD ( $\mathrm{PbB}$ ) MEASUREMENT

Blood lead was measured by a modification of the method described by Fernandez ${ }^{19}$ in a $1: 10$ 
whole blood dilution in $0.35 \mathrm{M}$ ammonium nitrate that contained $1 \%$ Triton-x -100 . The lead concentration was calculated by the method of standard addition, for which known amounts of lead are added to blood samples. In our laboratory, the lower limit of detection is 5 $\mu \mathrm{g} / \mathrm{dl}$, linearity is from 5 to $60 \mu \mathrm{g} / \mathrm{dl}$, and the coefficient of variation is $5 \%$. Past measurements of $\mathrm{PbB}$ were obtained from the worker's charts, and at least three measurements were available for each worker. As an index of total cumulative internal dose, the average concentration of $\mathrm{PbB}$ for each worker was multiplied by the number of years of exposure.

POSTURAL STABILITY MEASUREMENT

Postural stability was investigated with a computerised postural sway measurement system. The subjects were asked to stand on a four platter system, measurements were recorded from computerised elaboration of electronic signals emitted by four footplates, one for each heel and toe part, which are sensitive to vertical pressure produced by a straight standing subject in various positions. The subjects were tested for 20 seconds in five positions, (standing on the bare plates and plates with pads, both with opened and closed eyes) and standing on the footplates with the head tilted forward)).

The following measurements were obtained. (1) The general stability quotient (STQ), which is the amount of body oscillations summed over the four footplates, divided by the weight of the subject (the amplitude of the indices of postural sway is affected by vertical pressure, and therefore the division of the postural sway indices by the subject's weight is used in posturographic methodology to cancel out positive correlation of weight to amplitude). (2) Anterioposterior and lateral (APL) sway, which reflects correlations between the oscillations of paired traces of two among the four platform outputs. For assessing APL sway, four combinations of synchronies were calculated: between the two heels and two toe parts and between heel and toes of each foot. The correlation is a measure of the relative degree of APL sway compared with other motions and does not reflect the magnitude of the sway.

\section{STATISTICAL ANALYSIS}

The recordings were analysed blinded to whether the worker was from the control or exposed group. The group sample $t$ test was used to measure the significance of the differences in postural parameter scores between the lead workers and controls. To test for

Table 2 Comparison of body oscillations (STQ) and synchronisation of anterior posterior and lateral sway (APL sway) in workers exposed to lead compared with controls

\begin{tabular}{|c|c|c|c|c|}
\hline \multirow[b]{2}{*}{ Postural control } & \multicolumn{2}{|c|}{ Stability quotient } & \multicolumn{2}{|c|}{ Anterior posterior lateral } \\
\hline & $\begin{array}{l}\text { Exposed } \\
(n=63)\end{array}$ & $\begin{array}{l}\text { Controls } \\
(n=48)\end{array}$ & $\begin{array}{l}\text { Exposed } \\
(n=63)\end{array}$ & $\begin{array}{l}\text { Controls } \\
(n=48)\end{array}$ \\
\hline Basic position, open eyes & $13.2(3.3)$ & $12.6(3.7)$ & $27.6(7.6)$ & $29.2(8.2)$ \\
\hline Basic position, closed eyes & $18.2(5.4)^{\star \star}$ & $15.4(4.4)$ & $32.3(4.5)$ & $30.6(7.4)$ \\
\hline Standing on pads, open eyes & $14.2(4.3)$ & $14.4(4.4)$ & $27.6(9.8)$ & $26.8(8.8)$ \\
\hline Standing on pads, closed eyes & $21.0(5.8)$ & $20.9(6.0)$ & $30.9(4.4)$ & $29.4(7.0)$ \\
\hline Tilted head & $15.0(3.8)^{\star \star \star}$ & $13.3(3.7)$ & $28.8(6.4)$ & $25.9(10.0)$ \\
\hline
\end{tabular}

${ }^{\star \star} \mathrm{p} \leqslant 0.01 ;{ }^{\star \star \star} \mathrm{p} \leqslant 0.001$. acute and chronic effects of lead, we examined the association of postural parameter scores with the last venous blood lead concentration and the index of total cumulative internal dose, respectively. Dose-effect relations were tested by Pearson's correlation coefficients. Spearman's correlation coefficients were calculated to test the association between postural control of exposed and non-exposed workers with descriptor variables as they were not normally distributed. Linear regression was done with the exposure category as the major predictor variable after adding to the model all other variables which were significantly different $(\mathrm{p}<0.05)$ between the exposed and nonexposed groups. All analyses were performed with the SPSS (statistical package for social sciences) for windows.

\section{Results}

Exposed workers differed significantly from the controls for years of education, coffee consumption, and hours of sleep (table 1). Self rated health was of borderline significance (table 1). The exposed workers had significantly increased mean body oscillations (STQ measurements) standing on bare footplates with closed eyes $(p \leqslant 0.01)$, and with the head tilted forward $(p \leqslant 0.001)$ when compared with the controls (table 2). The APL sway with the workers standing on pads with open and closed eyes was not significantly increased in the exposed workers, but there was a trend for increased sway in all stress positions $(p=0.063)$. In the exposed workers smoking, hours of sleep, and alcohol intake were not significantly correlated with any of the measures of postural control, whereas age was associated with standing on pads with closed eyes only $(r=0.24, p=0.03)$. Significant but low correlations were found between the estimate of total exposure to lead and three of 10 of the postural control measurements, but between only one of the 10 measurements and present blood lead concentrations ( $r$ values ranged from 0.21 to $0.31, \mathrm{p} \leqslant 0.03$ ). After adding education, coffee consumption, hours of sleep, and self estimated health to the linear regression model, exposure was not significantly associated with increased body oscillations in the basic position with eyes closed (coefficient $=1.6(1.2), \mathrm{p}=0.18$ ), whereas the association of exposure with increased body oscillations when the head was tilted remained significant (coefficient $=2.25$ (0.84), $\mathrm{p}=0.0089)$. In neither case did any of the other variables significantly add to the model.

\section{Discussion}

Our study is not inconsistent with other studies which have shown that workers exposed to lead have decreased postural stability as indicated by increased sway. This was correlated with an estimated chronic internal dose but not acute blood lead concentrations. In battery workers exposed to lead, Chai et $a l^{17}$ found increased sway which did not correlate with either acute blood concentrations, or chronic blood concentrations, but rather with $\mathrm{PbB}$ concentrations measured over the preceding 2 years. We 
did find a significant correlation with the chronic internal dose, but the magnitude of the correlation was low. We did not, however, find increased sway when the subjects were standing on bare plates with their eyes open, but only when proprioreception inputs were blunted (standing on pads). This is consistent with the results of two previous studies, ${ }^{16}{ }^{17}$ but Yokoyana $e t a l^{18}$ found that workers exposed to lead stearate had increased sway at certain frequencies when standing on bare plates with their feet touching, either with their eyes open or closed, and the various measures of sway were correlated with either current lead concentrations or past lead absorption. Their study, however, is not directly comparable with ours as their workers stood with legs touching, and the workers were exposed to lead stearate which despite the lower blood lead concentrations in their workers compared with ours, may have had increased toxicity due to increased relative deposition of lead in the brain. ${ }^{20}$

This study is the first to show that increased oscillations are required to maintain balance in workers with eyes closed (interruption of the visual pathway) or with the head tilted (decreased vestibular input) when compared with controls. Further studies are warranted to substantiate our results and to determine the possible relevance of these findings - such as the correlation with decreased postural control and rates of accidents.

1 Discalzi GL, Capellaro F, Bottalo L, et al. Auditory brainstem evoked potentials (BAEPs) in lead-exposed workers. Neurotoxicology 1992;13:207-9.

2 Lille F, Margules S, Fournier E, et al. Effects of occupationa lead exposure on motor and somatosensory evoked potentials. Neurotoxicology 1994;15:679-83.
3 Zhang W, Zhang GG, He HZ, et al. Early health effects and biological monitoring in persons occupationally exposed to tetraethyl lead. Int Arch Occup Environ Health 1994;65: 395-9.

4 Tang HW, Liang YX, Hu XH, et al. Alteration of monoamine metabolises and neurobehavioral function in leadexposed workers. Biomed Environ Science 1995;8:23-9.

5 Schwartz BS, Bolla KI, Stewart W, et al. Decrements in neurobehavioral performance associated with mixed exposure to organic and inorganic lead. Am F Epidemiol 1993;137: 1006-21.

6 Jayaratman J, Devathasan G, Ong CN, et al. Neurophysiological studies on workers exposed to lead. $\mathrm{Br} \mathcal{F}$ Ind Med 1985;43:173-7.

7 Yeh JH, Chang YC, Wang JD. Combined electroneurographic and electromyographic studies in lead workers. graphic and electromyographic studies

8 Ashby J. A neurological and biochemical study of early lead poisoning. Br F Ind Med 1980;37:133-40.

9 Cavalleri A, Trimarchi F, Minoia C, et al. Quantitative measurement of visual field in lead exposed workers. In $\mathrm{R}$ Gilioli, MG Cassitto, V Foa, eds. Neurobehavioral methods in occupational health. Oxford: Pergamon Press, 1983:263-9.

10 Corsi G, Bartolucci GB, Fardin P, et al. Biochemical and electrophysiological study of subjects with a history of past lead exposure. Am F Ind Med 1984;6:281-90.

11 Hirata $M$, Kosaka, H. Effects of lead exposure on neurophysiological parameters. Environ Res 1993;63:60-9.

12 Lockitch G. Perspectives on lead toxicity. Clin Biochem 1993;26:371-81.

13 Matsumoto T, Fukaya Y, Yoshitomi S, et al. Relations between lead exposure and peripheral neuromuscular functions of lead-exposed workers: results of tapping test. Environ Res 1993;61:299-307.

14 Araki S, Murata K. Determination of evoked potentials in occupational and environmental medicine: a review. Environ Res 1993;63:133-47.

15 Linz DH, Barrett ET, Pflaumer JE, et al. Neuropsychologic and postural sway improvement after $\mathrm{Ca}^{++}$- EDTA chelation for mild lead intoxication. F Occup Med 1992;34:638-41.

16 Chia SE, Chua LH, Ng TP, et al. Postural stability of workers exposed to lead. Occup Environ Med 1994;51:768-71.

17 Chai SE, Chai HP, Ong CN, et al. Cumulative concentrations of blood lead and postural stability. Occup Environ Med 1996;53:264-8.

18 Yokoyama K, Araki S, Murata $\mathrm{K}$, et al. Subclinical vestibulo-cerebellar, anterior cerebellar lobe and spinocerebellar effects in lead workers in relation to concurrent and past exposure. Neurotoxicology 1997;18:371-80.

19 Fernandez FJ. Micromethod for lead determination in whole blood by atomic absorption with use of the graphite furnace. Clin Chem 1975;21:558-61.

20 Cavalleri A, Minoia C. Lead level of whole blood and plasma in workers exposed to lead stearate. Scand $\mathcal{F}$ Work Environ Health 1987;113:218-20. 